\title{
Life-cycle responses of a Mediterranean non-migratory cyprinid species, the Northern Iberian chub (Squalius carolitertii Doadrio, 1988), to streamflow regulation
}

\author{
Carlos M. Alexandre ${ }^{1}$ (D) | Maria T. Ferreira ${ }^{2}$ | Pedro R. Almeida ${ }^{1,3}$
}

${ }^{1}$ Universidade de Évora, MARE-Centro de Ciências do Mar e do Ambiente, Évora, Portugal

${ }^{2}$ Universidade de Lisboa, Centro de Estudos Florestais, Instituto de Agronomia, Lisboa, Portugal

${ }^{3}$ Universidade de Évora, Departamento de Biologia, Escola de Ciências e Tecnologia,

Évora, Portugal

Correspondence

Carlos M. Alexandre, MARE-Centro de Ciências do Mar e do Ambiente, Universidade de Évora, Largo dos Colegiais 2, 7004-516, Évora, Portugal.

Email: cmalexandre@fc.ul.pt

Funding information

Portuguese Science Foundation, Grant/Award Numbers: SFRH/BPD/108582/2015 and UID/MAR/04292/2013

\begin{abstract}
Streamflow is considered a driver of interspecific and intraspecific life-history differences among freshwater fish. Therefore, dams and related flow regulation can have deleterious impacts on their life cycles. The main objective of this study was to assess existing differences in the growth and reproduction patterns of a non-migratory fish species (the Northern Iberian chub, Squalius carolitertii, Doadrio, 1988), between nonregulated and regulated watercourses. For 1 year, samples were collected from two populations of Iberian chub, inhabiting rivers with nonregulated and regulated flow regimes. Flow regulation for water storage promoted changes in chub's condition, duration of spawning, fecundity, and oocyte size. However, this non-migratory species was less responsive to streamflow regulation than other native potamodromous species. Findings from this study are important to understand changes imposed by regulated rivers and can be used to support the implementation of suitable river management practices.
\end{abstract}

\section{KEYWORDS}

dams, life history, Mediterranean rivers, Northern Iberian chub, streamflow regulation

\section{1 | INTRODUCTION}

Streamflow patterns have a major influence on shaping the life history strategies of aquatic species (Poff et al., 1997). Although it is well stablished that temperature regimes influence the life-cycle patterns of many stream and river animals (Olden \& Naiman, 2010), the influence of water level fluctuations and flow disturbances, as well as its frequency, intensity, and timing, is also important for the life-cycle development of most existing groups of freshwater biota (Resh et al., 1988). Seasonal timing and predictability of natural flow regimes are particularly critical because the life cycles of many aquatic species are timed to avoid or take advantage of specific flow conditions (Poff et al., 1997). For freshwater fishes, flow plays an important role in the lives of species with critical life events linked to flow regime (e.g., reproduction, spawning behaviour, larval survival, growth patterns, and recruitment; Humphries, King, \& Koehn, 1999; Junk, Bayley, \& Sparks, 1989). Many of these life events are synchronized with temperature and day length such that changes in flow regime that are not in natural harmony with these seasonal cycles may have a negative impact on aquatic biota (Bunn \& Arthington, 2002).

Streamflow alterations resulting from dam construction and regulation can take many different forms, usually according to the type of river where these infrastructures are built or their operation mode and purpose (Bunn \& Arthington, 2002). Although some type of dams tends to homogenize and stabilize river flow (i.e., storage or flood control dams), others may cause an inversion of the natural streamflow pattern, with higher flows in summer and lower flows in winter (i.e., irrigation dams) and others, like hydroelectric facilities, affect the natural rate of environmental change, usually causing extreme and unpredictable daily variations in water level and available habitat (for a review of the effects of different types of dams check,e.g., Poff \& Zimmerman, 2010; Arthington, 2012; Alexandre, 2014). Thus, considering the link between fish life cycle and flow patterns, dam operation that significantly artificialize riverine flow regimes can result in effective and persistent effects on fish faunas at local and regional scales (Olden \& Naiman, 2010). For example, in cases where fish species 
use seasonal peak flows or floodings as a cue for egg hatching, migration, or spawning, river regulation that eliminates or reduces these peaks can directly impair local populations of such species (Naesje, Jonsson, \& Skurdal, 1995; Welcomme et al., 2006).

Life-history characteristics of riverine fish are well studied and wellsuited as a platform to test general relationships between flow regime and biological communities (e.g., Alexandre, Ferreira, \& Almeida, 2015; Lamouroux, Poff, \& Angermeier, 2002; Mims \& Olden, 2012, 2013; Winemiller \& Rose, 1992). However, most models and other studies addressing this relationship were developed to analyse variability in life-cycle traits at the assemblage level, and the aspects of the links between fish bioecological cycles and environment remain relatively unknown at the population level. Intraspecific variability in the life histories of fish determined by environmental conditions has been demonstrated to occur in numerous cases (e.g., Alexandre, Ferreira, et al., 2015; Alexandre, Sales, Ferreira, \& Almeida, 2015; Blanck, Tedesco, \& Lamouroux, 2007; Spranza \& Stanley, 2000). Described patterns are, generally, in accordance to previous theories about fish life-history strategies (Winemiller \& Rose, 1992) and include changes in diet composition and feeding strategy (Alexandre, Sales, et al., 2015); differences in age at first reproduction due to flow effects or food availability (Alexandre, Ferreira, et al., 2015), longevity (Baltz \& Moyle, 1984), brood size, and size at first reproduction (Baylis, Wiegman, \& Hoff, 1993).

The majority of the existing studies linking fish life-history strategies with natural and artificial streamflow variability, caused by regional differences or dam construction and operation, have been conducted mostly in North American basins, for large migratory species (especially salmonids) or across small areas with different habitat types (e.g., Mims \& Olden, 2012, 2013), and there is a scarce number of studies dealing with intraspecific and population-based differences in life histories of Mediterranean cyprinids, across large-scale gradients of streamflow variability, particularly the bioecologic deviations related with the effect of human-altered streamflows (e.g., Torralva, Puig, \& Fernández-Delgado, 1997; Weisberg \& Burton, 1993). Recently, a study by Alexandre, Ferreira, et al. (2015), developed in several nonregulated and regulated Mediterranean watercourses, identified significant differences in growth and reproduction patterns, as well as somatic condition and longevity, for a cyprinid fish species from the Iberian Peninsula, for which the authors gave credit to the streamflow regulation operated by two different types of dams. This study, however, was focused on a typical large potamodromous species, the Iberian barbel (Luciobarbus bocagei Steindachner, 1864), which is highly plastic, in phenotypic terms, and responsive to environmental variability, and it remains to be evaluated if a similar level of response also happens in smaller, more resident, species, which are not so dependent of flow cues to complete their life-cycles.

The main objective of the present study is to assess the differences in life-history characteristics of a typical Mediterranean nonmigratory fish species, the Northern Iberian chub (Squalius caroliterti Doadrio, 1988), between nonregulated and regulated rivers from southern Europe. This species is a small (maximum recorded sizes are approximately $35 \mathrm{~cm}$ ) cyprinid, endemic to the Iberian Peninsula, that occurs in nearly all river basins from north and central Portugal. It is a generalist species in terms of habitat preferences, but its specific dietary (i.e., invertivorous) and reproductive (i.e., lithophilic) requirements (Maia, Maia, Pires, \& Valente, 2006; Santos, Godinho, \& Ferreira MT Cortes, 2004) make this species potentially susceptible to environmental changes like the ones caused by flow regulation. More specifically, this study aims to (a) assess the response of age, growth, and reproduction traits of this non-migratory fish species to a regulated flow regime imposed by a dam operating for water storage purposes; (b) evaluate the degree of biological deviation related with this type of flow regulation, by comparing the regulated scenario to the species life-cycle responses in a nonregulated river; and (c) evaluate the relationship between the biological cycles of the target species and several flow components.

Although being usually less studied than large migratory species, resident fish species, like the Iberian chub, have drawn the attention of conservation agencies and management authorities because they usually exhibit a high rate of decline linked to environmental perturbation (Maia et al., 2006). In addition, these species now afford legislative protection under the European Water Framework Directive, which demands unrestricted movements for all fish species and size classes. Therefore, it is essential to study their responses to environmental disturbance, especially the one caused by anthropogenic actions, such as dam construction and operation, whose role and effects on aquatic ecosystems can be mitigated through suitable management actions.

\section{2 | METHOD}

\section{1 | Study area}

This study was conducted in two river systems (Figure 1), one regulated and other nonregulated, located in the northwestern part of the Iberian Peninsula, an area with strong Atlantic influence where rivers have a permanent flow throughout the year, which contrasts with the rest of the region where rivers tend to follow the traditional Mediterranean pattern of drying during summer periods. River systems were selected following a criterion of minimum evidence of human disturbance (flow regulation aside) such as physical habitat modifications, point sources of pollution or agricultural run-off.

The "treatment river" selected to assess the responses of chub's life cycle in a flow regulation context was River Homem (regulated river [RR]), located in the Cávado river basin, which has approximately $49 \mathrm{~km}$ of extension and a drainage area of $257 \mathrm{~km}^{2}$ (SNIRH, 2013). Since 1972 , its flow is being regulated by Vilarinho das Furnas dam, which is operated mainly for water storage for its larger and more productive counterpart, Caniçada Dam. Vilarinho das Furnas releases a constant hypolimnetic flow (mean daily effluent discharge of $4 \mathrm{~m}^{3} \mathrm{~s}^{-1}$ from June to September and $10 \mathrm{~m}^{3} \mathrm{~s}^{-1}$ from October to May), set to fulfil minimum ecological flow requirements (environmental flow regime [EFR]), which reduces and homogenizes downstream river flow, while severely diminishing the variability of habitual and extreme values throughout the year. To act as "reference" in this study, we selected River Vez (nonregulated river [NRR]), a NRR located in River Lima basin, with $38 \mathrm{~km}$ of length and a drainage area of $264 \mathrm{~km}^{2}$. Despite being in distinct river basins, both studied rivers are similar in terms of abiotic and biotic (i.e., fish assemblage) typologies (Alexandre, Ferreira, \& Almeida, 2013; 


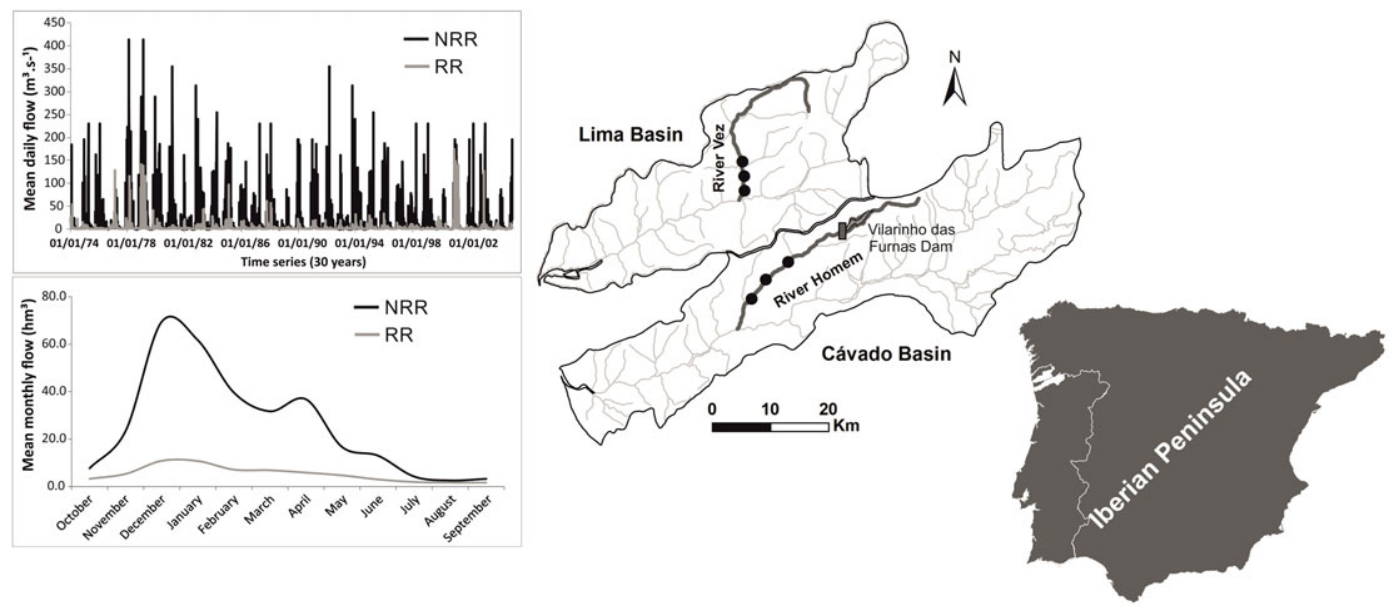

FIGURE 1 Location of the study area in both river systems, sampling sites $(\bullet)$ in the selected regulated and nonregulated rivers and respective hydrograms of mean daily discharge $\left(\mathrm{m}^{3} \mathrm{~s}^{-1}\right)$ and monthly flow volume $\left(\mathrm{hm}^{3}\right)$. In the charts presented, - and - represent, respectively, the nonregulated (NRR) and regulated (RR) watercourses of each system

INAG I. P., 2008; Matono et al., 2009), which allows to compare them, with a high level of confidence.

A more detailed characterization of the studied rivers and of the main streamflow (30-year time series, 1974-2004, collected from the Portuguese Environmental Agency Database; SNIRH, 2013) and thermal (obtained with data loggers Water Temp Pro V2 from HOBO during the study period) regimes differences between them is presented by Alexandre et al. $(2013,2015)$ and Alexandre, Sales, et al. (2015). In short, only slight differences are observed between the two rivers regarding their seasonal temperature variation pattern, which occur mostly in the end of spring and summer when the NRR presents higher average daily temperatures. This thermal differences are probably related with local climate variability and not resulting directly from potential effects of the EFR released by Vilarinho das Furnas dam, because a strong correlation (Spearman rank correlation; rho $>0.90, p$ value $<0.05$ ) exists between mean monthly temperature values of this river and the respective local air temperature registered in the closest meteorological station (SNIRH, 2013).

Regarding streamflow regime, the regulation for storage purposes in the RR is affecting its flow regime by reducing and homogenizing the magnitude of the annual and monthly volumes and variability of habitual and extreme flow values throughout the year, when compared with the NRR river (Figure 1). The mean annual flow volume of the NRR is $371.59 \mathrm{hm}^{3}$, much higher than the value observed for the RR $\left(82.94 \mathrm{hm}^{3}\right)$. This type of regulation is also affecting, in a way, the flood season by severely reducing the frequency, duration, and magnitude of the maximum daily flow volume registered (NRR: $224.30 \mathrm{hm}^{3}$; RR: $43.74 \mathrm{hm}^{3}$ ), the effective discharge (flood with power to change the geomorphology of the river; NRR: $210.30 \mathrm{hm}^{3}$; RR: $58.88 \mathrm{hm}^{3}$ ), and the variability of floods, among others. This streamflow characterization was performed using IARHIS 2.2, a methodology developed by Santa-Maria and Yuste (2010).

\section{2 | Collection of fish data}

In each selected river, fish samples were taken from three distinct sites (Figure 1). Sampling sites in NRR and RR were equally distributed
( $\sim 2 \mathrm{~km}$ from each other). In RR, sites were located downstream of the dam ( $\geq 3 \mathrm{~km}$ ) but before the entry of any major tributary to avoid the significant amelioration of regulation effects in flow regime. Fish samples were taken from three independent sites only to increase population representativeness, and these sites were never analysed as independent samples to avoid pseudoreplication issues. For replication purposes, individual fish/river combinations were considered.

An electrofishing (Hans Grassl EL 62 generator DC, 600 V) sampling method was used to collect (average sample time of $1 \mathrm{hr}$ in each site-sampling campaign combination) bimonthly samples of Northern Iberian chubs between May 2010 and June 2011 (2010-2011 is considered a normal year in terms of climate conditions, namely, temperature and precipitation; IPMA I.P., 2011). During the theoretical reproductive period of the target species (March-June; Maia et al., 2006), sampling was fortnightly. In total, 321 chubs were caught in the studied rivers (NRR: 183; RR: 138). All fish samples were immediately placed on ice until they were stored at $-10^{\circ} \mathrm{C}$ in the laboratory, where their total length $\left(L_{t}, \pm 1 \mathrm{~mm}\right)$ and weight $\left(W_{t}, \pm 0.01 \mathrm{~g}\right)$ were measured. After the complete removal of the viscera, fish were again weighed (eviscerated body mass, $W_{\mathrm{e}}, \pm 0.01 \mathrm{~g}$ ). Gonads were removed, visually inspected for sex determination (males, females, or immature), and their weight $\left(W_{\mathrm{g}}, \pm 0.01 \mathrm{~g}\right)$ was determined. Gonads from female chubs captured in the two studied rivers (NRR: $n=22$; RR: 19) during the theoretical peak of their reproductive cycle (i.e., May and June 2011; Maia et al., 2006) were weighed and placed on a $4 \%$ solution of neutralized formaldehyde and, after 3 days, washed with distilled water and preserved in $96 \%$ ethanol for the analysis of fecundity and oocyte size distribution. From different sections of each pair of preserved ovaries, five subsamples of approximately similar weight were weighed and stored in alcohol. Subsamples were shaken periodically to aid oocyte separation. The total number of oocytes in each gonadal subsample was counted for fecundity determination, and 100 oocytes randomly chosen from each subsample were also measured for size distribution analysis $( \pm 0.001 \mathrm{~mm})$, using a digital camera (LEICA DFC 280), coupled to a stereomicroscope (LEICA MZ6), and the image analysis program LEICA Application Suite 4.1.0 (LEICA Microsystems). 
From each sampled chub, 20 scales from the left side of the body, between the dorsal fin and lateral line, were removed for age determination. Scales were cleaned using a $10 \% \mathrm{NaOH}$ solution, dried, mounted between two glass slides, and projected under constant magnification (20x). The best scale of each fish was chosen and all the measurements were made on it. The number of annulus (fish age) was counted, and the total scale radius, as well as the distance from the focus to each annulus, was measured on the lateral-ventral field of each fish scale.

\section{3 | Age and growth}

The relationship between scale radius and fish total length was fitted for each of the studied chub populations using a linear regression model. Because estimated intercepts (constant $a$ ) were significant for the two modelled relationships ( $p<0.05$ ), we rejected the null hypothesis that these intercepts were not different from 0 and included them in the respective age-length back calculations as an estimate of the Fraser-Lee correction factor (considered as the fish length at scale formation). Back calculations were performed separately for each population using the Fraser-Lee equation (Bagenal \& Tesch, 1978):

$$
L_{i}=\frac{L_{t}-a}{S_{c}} \times S_{i}+a
$$

where $L_{i}$ is the length at annulus formation, $L_{t}$ is the total fish length at capture, $S_{\mathrm{i}}$ is the radius at annulus formation, $S_{\mathrm{c}}$ is the overall radius, and $a$ is the regression intercept or the size of the individual at the time of scale formation determined for each population. Sex and population/river effects in the back-calculated lengths-at-age were evaluated by an analysis of covariance (ANCOVA), to test the null hypothesis of no differences between rivers or sexes in the obtained length-at-age relationships.

Annual increments and instantaneous growth rates (Bagenal \& Tesch, 1978) were obtained from back-calculated lengths. Population/River and Sex effects in fish back-calculated annual increments were tested using an ANCOVA, to test the null hypothesis of no differences between rivers or sexes in chub's growth. It is a well-known fact that fish growth rate is intimately related with fish age and size, because this parameter usually declines when fish get older and bigger (Bagenal \& Tesch, 1978). Therefore, to account for age or size effect in these comparisons, we included estimated fish length-at-age as covariate, as well as its interaction with main tested factors (population/ river and sex), in the ANCOVA analysis. This analysis was followed by Tukey Honestly Significant Difference (HSD) post hoc tests to identify significantly different levels within the tested factors.

Periodicity of annulus deposition, and consequently, scale reading procedure, and subsequent analysis were validated by marginal increment analysis (MIA; Bagenal \& Tesch, 1978), defined as

$$
M I A=\frac{S_{c}-Y_{i}}{Y_{i}-Y_{i-1}}
$$

where $Y_{\mathrm{i}}$ is the radius of the last annulus, $Y_{\mathrm{i}-1}$ is the radius of the penultimate annulus, and $S_{c}$ has the same meaning as before. Mean MIA values ( \pm standard deviation) for each sampling campaign, together with the instantaneous increment rates between sampling campaigns, were used to analyse seasonal growth of the two studied populations.
Significance of intra-annual variations of MIA was evaluated by a oneway analysis of variance (ANOVA), using month as the single fixed factor, followed by Tukey HSD post hoc tests to identify significant growth periods.

Observed fish lengths, and respective ages, at capture were used to determine von Bertalanffy growth equations for the two studied populations, as following:

$$
\mathrm{L}_{\mathrm{t}}=\mathrm{L}_{\infty}\left(1-\mathrm{e}^{-\mathrm{K}\left(\mathrm{t}-\mathrm{t}_{0}\right)}\right)
$$

where $L_{t}$ is the length at time t, $L_{\infty}$ is the asymptotic length, $K$ is a growth coefficient, and $t_{0}$ is a time coefficient at which length would theoretically be 0 . Von Bertalanffy analyses were conducted separately for males and females of each population, and immature fish were included in each sex for both procedures. Equations were fitted, and parameters were estimated using the "Analysis of Length-at-age data" option included within the package FISAT II-Fish Stock Assessment Tools, v1.2.2., developed by FAO-ICLARM (Gayanilo, Sparre, \& Pauly, 2004).

Weight-length relationship was also analysed and compared between the two studied populations. As for von Bertalanffy estimates, immature chubs were also included in each sex in the following procedures. Total length and eviscerated weight (i.e., to remove biases related with gonad maturation and feeding patterns) values were log transformed to achieve data linearity, and the models were fitted using linear regression procedures, as the following equation:

$$
\log \left(W_{\mathrm{e}}\right)=\log (a)+b \times \log \left(L_{\mathrm{t}}\right)
$$

where $b$ and $\log (a)$ are, respective, the slope and the intercept of the relationship; $W_{\mathrm{e}}$ is the eviscerated weight; and $L_{\mathrm{t}}$ represent the same as before. Inferences about the slope of each linear model, representing the type of growth exhibited by the fish, were performed using a $t$ test of mean difference against a constant value of 3 (isometric growth). Comparisons of weight-length relationship between chubs' population/river and sex were performed using an ANCOVA.

\section{4 | Reproduction}

Age and length at first maturation were determined separately for male and female chubs from the nonregulated and regulated rivers following two main criteria:

a. age and total length of the youngest and smallest fish exhibiting gonads on stages III, IV, V, or VI of maturation (Murua et al., 2003);

b. age class and respective mean total length, in which at least $10 \%$ of the fish exhibit gonads on stages III, IV, V, or VI of maturation (Murua et al., 2003).

Gonadal development cycle was assessed separately for male and female chubs captured in each river/campaign combination using the gonadossomatic index (GSI):

$$
G S I=\frac{W_{g}}{W_{e}} \times 100 .
$$

To statistically compare this index between the two studied populations in each sampling campaign $t$-test analyses were used. 
Univariate and multivariate one-way PERMANOVA (add-on package PERMANOVA for PRIMER+v6.0; Anderson, Gorley, \& Clarke, 2008) showed the absence of significant differences in, respectively, oocyte number and size frequency distribution $(0.1 \mathrm{~mm}$ size classes, between 0 and $2.4 \mathrm{~mm}$ ), regarding their position in the ovary, so all five subsamples taken from each fish were used in the subsequent analyses. Fecundity was determined for each individual female, using the gravimetric method, as the product of mean oocyte density and gonad weight, as the following equation:

$$
F=\frac{\left(\sum_{i} \frac{O_{i}}{W_{i}}\right)}{n} \times W_{g},
$$

where $O_{i}$ is the total number of oocytes in a subsample, $W_{i}$ is the weight of the respective subsample, $n$ is the number of subsamples taken (i.e., five), and $W_{\mathrm{g}}$ is the same as before. Differences in fecundity and oocyte size distribution between the two studied chub populations were tested by means of, respectively, univariate and multivariate one-way PERMANOVA, considering population/river as the only fixed factor and fecundity and oocyte size classes as dependent variables. Oocyte size classes occurring in less than $5 \%$ of the samples were removed. Some studies on cyprinids (e.g., Fernández-Delgado \& Herrera, 1995; Herrera \& Fernández-Delgado, 1992; Maia et al., 2006) reveal a strong relationship of fecundity and oocyte size with fish length; therefore, we included individual total length $\left(L_{t}\right)$ of analysed females as a covariate to test its effect on the variability of these two parameters.

\section{5 | Relationship with environmental components}

The hydrological characterization presented before in this manuscript, which was performed with IAHRIS 2.2, plus a Time Series Analysis (River Analysis Package version 1.3.0; Marsh, Stewardson, \& Kennard 2006) on the same flow time series for both rivers, allowed us to obtain a total of 27 monthly (January to December) hydrologic metrics, all of them with potential to be representative of the degree of hydrological alteration caused by the river regulation source (i.e., Vilarinho das Furnas Dam) analysed in this study. Initial screening (Spearman rank correlation, rho) showed strong correlation among many of these metrics (above a cut-off value of 0.80). To avoid redundancy among the tested hydrological predictors, when two or more variables were considered highly correlated, only one of them was selected. Following this selection procedure, from the initial set of potential predictors, 10 final hydrological metrics (Table 1) were selected, describing ecologically important aspects of the flow regime and its alterations in the studied systems.

Despite river hydrology, and its regulation, being the main focus of this study, thermal regime is often considered of high importance for the development of fish life cycles. However, previous analysis of thermal patterns within the study area showed that they are similar between both rivers, decreasing its importance for the biological differences and responses that we are looking for in this study. To confirm this assumption, we added an 11th environmental variable to the list of potential predictors, the mean monthly temperature (Temp), to evaluate its potential joint effect with streamflow components in the intra-annual variation of chub's life-cycle parameters.

Stepwise multiple linear regressions $(P$ to enter $=0.05 ; P$ to remove $=0.10$ ) were used to relate the 11 final environmental variables with chub's annual reproductive cycle, expressed as the GSI and seasonal growth, expressed as instantaneous MIA increments between sampling campaigns. For seasonal growth analyses, the period in which the new annulus was deposited was ruled out, because the accentuated decrease in marginal width cannot be considered an alteration of fish growth pattern (Bagenal \& Tesch, 1978).

For all the statistical analyses described in this study, assumptions for the use of appropriate parametric methodologies were previously tested and, in case of non-fulfilment even after suitable data transformation, the equivalent non-parametric analysis was employed. Except

TABLE 1 Streamflow and temperature variables and respective range of values for each studied river during the entire study period (mean monthly values), selected to assess the relationship between the environmental variability within the study area and chub's reproductive and growth seasonal cycles

\begin{tabular}{llll} 
Streamflow variables (unit) & Code & Nonregulated river (River Vez; NRR) & Regulated river (River Homem; RR) \\
\hline Monthly volume $\left(\mathrm{hm}^{3}\right.$ ) & MonthVol & $2.56-61.72$ & $1.65-10.75$ \\
No. of high flow days (days) & HFlowDays & $0.00-2.20$ & $0.00-0.00$ \\
\hline Flow variability $\left(\mathrm{Q}_{10 \%}\right.$-Q90\%) & Var & $1.20-2.49$ & $0.47-1.67$ \\
No. of null flow days (days) & ZFlowDays & $0.00-4.58$ & $0.00-0.00$ \\
\hline Duration of high spell peaks (days) & DHSpelPeak & $0.00-3.54$ & $0.00-8.27$ \\
Magnitude of low spell troughs (m s ${ }^{-3}$ ) & LSpelTrough & $0.00-0.39$ & $0.00-0.53$ \\
\hline Duration of low spell troughs (days) & DLSpelTrough & $0.00-17.76$ & $0.00-12.27$ \\
Period between low spells (days) & PBLSpel & $0.00-13.00$ & $0.00-6.50$ \\
\hline Duration of falls (days) & DFalls & $6.32-13.89$ & $4.97-9.31$ \\
Baseflow (m s ${ }^{-3}$ ) & BsFlow & $0.36-0.78$ & $0.62-0.84$ \\
\hline Mean monthly temperature $\left({ }^{\circ} \mathrm{C}\right)$ & Temp & $9.95-22.20$ & $10.48-20.33$
\end{tabular}

Note. Monthly volume, mean flow (q) volume for a given month; No. high flow days, average number of days with flow above the $5 \%$ percentile in the flow duration curve ( $q \geq Q_{5 \%}$ ) for a given month; Flow variability, average difference between $Q_{90 \%}\left(90 \%\right.$ percentile) and $Q_{10 \%}(10 \%$ percentile) in the flow duration curve for a given month; No. of null flow days, average number of days with zero flow $(q=0)$ for a given month; Duration of high spell peaks, average duration of periods with flow values above a defined threshold ( $q \geq Q_{5 \%}$ ); Magnitude of low spell troughs, the mean flow value for the periods below a defined threshold ( $\mathrm{q} \leq \mathrm{Q}_{5} \%$ ); Duration of low spell troughs, average duration of periods with flows below a defined threshold ( $\mathrm{q} \leq \mathrm{Q}_{95 \%}$ ); Period between low spells, the mean time between temporally spaced periods with flows below a given threshold ( $q \leq$ Q $_{95 \%}$ ); Duration of falls, sum of the duration of all flow falls (i.e., flow decreases) for the analysis period divided by the total number of flow falls; Baseflow, flow which occurs in the absence of runoff due to rainfall events, here as the ration between total baseflow discharge and total discharge, for a given month. 
for PERMANOVA, all statistical analyses were conducted with STATISTICA 13.0 (StatSoft, Inc.).

\section{3 | RESULTS}

\subsection{Age and growth}

MIA validated the annual deposition of the annulus in chubs' scales for the two studied populations. Annulus formation occurred in the beginning of May for the two populations and sexes (Figure 2). Male chubs inhabiting the NRR presented a total of six age groups whereas females from the same population exhibited seven age groups. Seven age groups were also found for male and female chubs inhabiting the RR.

The ANCOVA performed on the back-calculated length-at-ages obtained for the two populations and sexes revealed significant effects of $\operatorname{sex}\left(F_{2,901}=7.23 ; p<0.001\right)$ but not population $/$ river $\left(F_{1,901}=1.33 ; p>0.05\right)$, on the length-at-age relationship of tested chubs. Besides this, only the interaction term of sex with the covariate age (i.e., back-calculated annulus increment number) was significant $\left(F_{1,901}=24.22 ; p<0.001\right)$, revealing that the slopes of the tested regressions were only significantly different between male and female chubs and not between NRR and RR populations. Therefore, we chose to present length-at-age data separately for male and female chubs within each studied river (Table 2) and to perform following growth analysis and comparisons independently for each sex.

The ANCOVA performed to identify population/river and sex effects on chub annual growth (i.e., back-calculated annual increments) identified a significant effect of the covariate length-at-age $\left(F_{1,580}=10.71 ; p<0.05\right)$, confirming the strong relationship between chub's growth and respective age or size. This analysis also identified a significant effect of $\operatorname{sex}\left(F_{2,580}=5.15 ; p<0.05\right)$ but not of population/river $\left(F_{1,580}=2.66 ; p>0.05\right)$ on chubs' annual growth. None of the tested interactions, between factors or with covariate, had significant effects on fish growth. Additional Tukey HSD tests on the levels of significant factor sex showed that female chubs exhibit a higher annual growth when compared with males, independently of the river or population they come from.

Von Bertalanffy growth equations and parameters estimated for each population using observed fish lengths, and respective ages at capture, corroborated the results previously obtained from the ANCOVA of back-calculated annual increments, showing that differences in growth rate $(k)$ and maximum potential length (asymptotic length, $L_{\infty}$ ) were higher between sexes than between populations/rivers studied. In accordance with the equations and parameters presented below (i.e., parameters of interest signalled in bold), within both populations, independently of the level of flow regulation they were subjected to, female chubs showed higher growth rates and have the potential to achieve larger sizes than males.

$$
\begin{aligned}
& \text { NRR Males }(n=142) \rightarrow L_{t}=184.7\left(1-e^{-0.30(t)}\right) \\
& \text { NRR Females }(n=127) \rightarrow L_{t}=251.8\left(1-e^{-0.35(t)}\right) \\
& R R \text { Males }(n=94) \rightarrow L_{t}=170.1\left(1-e^{-0.34(t)}\right) \\
& \text { RR Females }(n=89) \rightarrow L_{t}=284.6\left(1-e^{-0.37(t)}\right)
\end{aligned}
$$

Seasonal growth analysis, based on the instantaneous MIA increments, revealed, once again, that differences in growth patterns, this time analysed at a reduced temporal scale (i.e., seasonal), are mostly between sexes rather than between chub populations subjected, or not, to flow regulation (Figure 2). Even between sexes, differences in seasonal growth pattern are slightly noticeable and may reflect only small gender-related anticipations and/or delays constrained by the

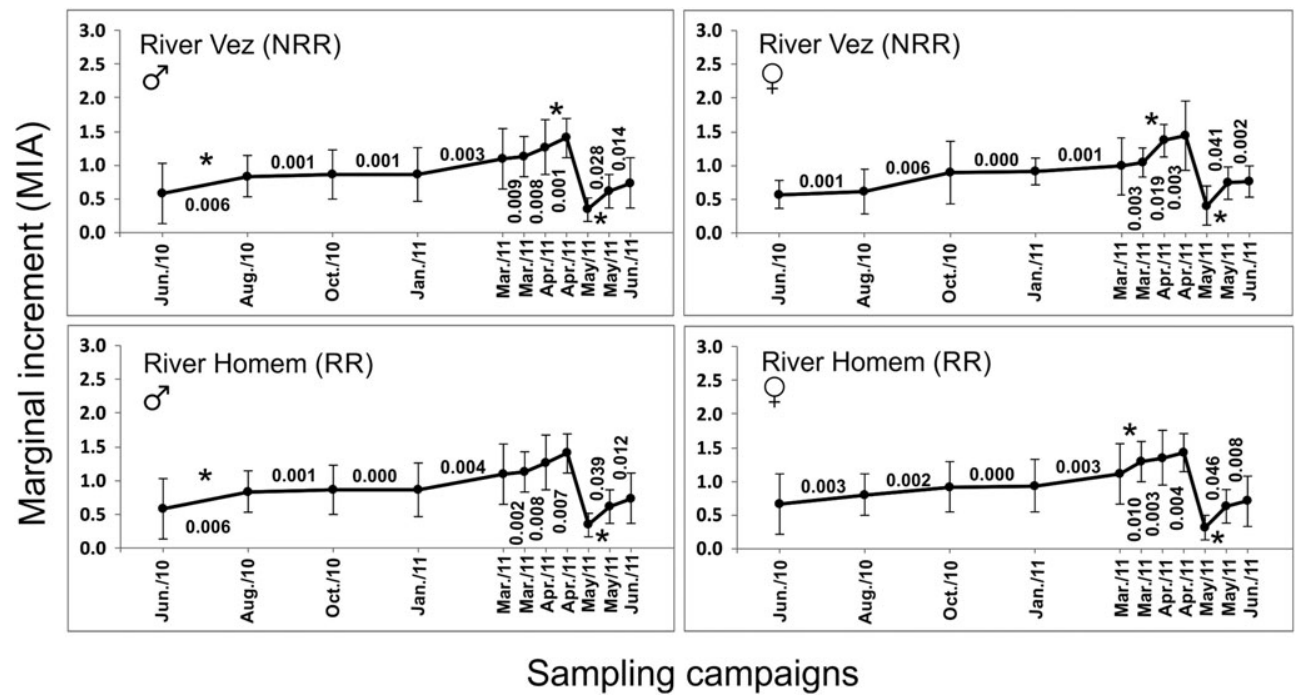

FIGURE 2 Seasonal variation of marginal increments (MIA; mean \pm standard deviation), obtained from the scales of male ( $(3)$ and female (ㅇ) chubs from the two studied populations or rivers. Instantaneous increment rates between sampling campaigns are also indicated and ${ }^{*}$ shows statistically significant intra-annual variations of MIA (ANOVA; $P<0.05$; Tukey HSD tests). ANOVA: analysis of variance; MIA: marginal increment analysis; NRR: nonregulated river; RR: regulated river 
TABLE 2 Back-calculated total lengths (mean total length, $\mathrm{mm}$ ) for male and female chubs from the two studied populations or rivers (NRR: River Vez and RR: River Homem), with data from another study with the same species (Maia et al., 2006; mean fork length, mm) given for comparison

\begin{tabular}{|c|c|c|c|c|c|c|c|c|c|c|c|c|c|}
\hline & I & & II & & III & & IV & & V & & VI & & VII \\
\hline $\begin{array}{l}\text { Studied populations } \\
\quad \text { River Vez (NRR)-Males }\end{array}$ & 52 & & 71 & & 92 & & 112 & & 122 & & 131 & & \\
\hline $\begin{array}{l}\text { Annual increment } \\
\text { Instantaneous growth rate }\end{array}$ & & $\begin{array}{l}19 \\
0.31\end{array}$ & & $\begin{array}{l}21 \\
0.26\end{array}$ & & $\begin{array}{l}20 \\
0.20\end{array}$ & & $\begin{array}{l}10 \\
0.08\end{array}$ & & $\begin{array}{l}9 \\
0.07\end{array}$ & & & \\
\hline $\begin{array}{l}\text { River Vez (NRR)-Females } \\
\text { Annual increment }\end{array}$ & 52 & 21 & 73 & 22 & 95 & 25 & 120 & 24 & 144 & 20 & 164 & 19 & 183 \\
\hline $\begin{array}{l}\text { Annual increment } \\
\text { Instantaneous growth rate }\end{array}$ & & $\begin{array}{l}18 \\
0.31\end{array}$ & & $\begin{array}{l}19 \\
0.25\end{array}$ & & $\begin{array}{l}20 \\
0.21\end{array}$ & & $\begin{array}{l}18 \\
0.16\end{array}$ & & $\begin{array}{l}17 \\
0.13\end{array}$ & & $\begin{array}{l}17 \\
0.11\end{array}$ & \\
\hline $\begin{array}{l}\text { River Homem (RR)-Females } \\
\text { Annual increment }\end{array}$ & 51 & 21 & 72 & 21 & 93 & 26 & 119 & 28 & 147 & 22 & 169 & 27 & 196 \\
\hline $\begin{array}{l}\text { Instantaneous growth rate } \\
\text { Other studies }\end{array}$ & & 0.34 & & 0.25 & & 0.25 & & 0.21 & & 0.14 & & 0.15 & \\
\hline
\end{tabular}

Note. NRR: nonregulated river; RR: regulated river.

${ }^{a}$ Maia et al. (2006).

respective peak of reproductive season. In general, in terms of seasonal growth chubs from both sexes and rivers exhibited two distinct periods. A period of significant growth during spring, between March and June, which is coincident with the species reproductive season, and a second period of reduced, or almost indistinguishable, during the end of summer, autumn, and winter. The period of accentuated and statistically significant growth (ANOVA; $p<0.05$; ${ }^{*}$ ) during spring seems to start earlier (i.e., approximately 1 month) in females than in males, for both rivers. Multiple regressions revealed that seasonal MIA increments were not significantly related to any of the environmental variables used in these analyses as potential predictors for this biological cycle, implying that seasonal growth of male and female chubs is poorly responsive to environmental variation, or, is somehow related to other variables not included in this study.

Regarding the log-transformed (i.e., linear) weight-length relationship for males and females of the studied populations (Table 3; Figure 3 for graphic representation of linear weight-length relationships for both populations/rivers), $t$ tests between the estimated slopes and the constant 3 (defined as isometric fish growth) revealed the existence of a significantly different type of growth between the two studied populations, which was consistent for both sexes. Whereas male and female chubs from NRR exhibited a growth type

TABLE 3 Linear weight-length regression coefficients $\left[\log \left(W_{\mathrm{e}}\right)=\log (a)+b \times \log \left(L_{\mathrm{t}}\right)\right]$ estimated for male and female chubs in the two studied systems

\begin{tabular}{|c|c|c|c|c|c|}
\hline Population/river & Sex & No. of fish & $\log (a)$ & b & Adjusted $R^{2}$ \\
\hline \multirow[t]{2}{*}{ River Vez (NRR) } & $\hat{\sigma}$ & 142 & -11.77 & 3.04 & 0.96 \\
\hline & q & 127 & -11.78 & 3.04 & 0.98 \\
\hline \multirow[t]{2}{*}{ River Homem (RR) } & $\hat{\sigma}$ & 94 & -12.58 & 3.21 & 0.99 \\
\hline & 우 & 91 & -12.51 & 3.19 & 0.99 \\
\hline
\end{tabular}

Note. Immature chubs were included in both sexes. Slopes (b) significantly different ( $t$ test; $p$-value < 0.05) from three (isometric growth) are highlighted in bold. NRR: nonregulated river; RR: regulated river.

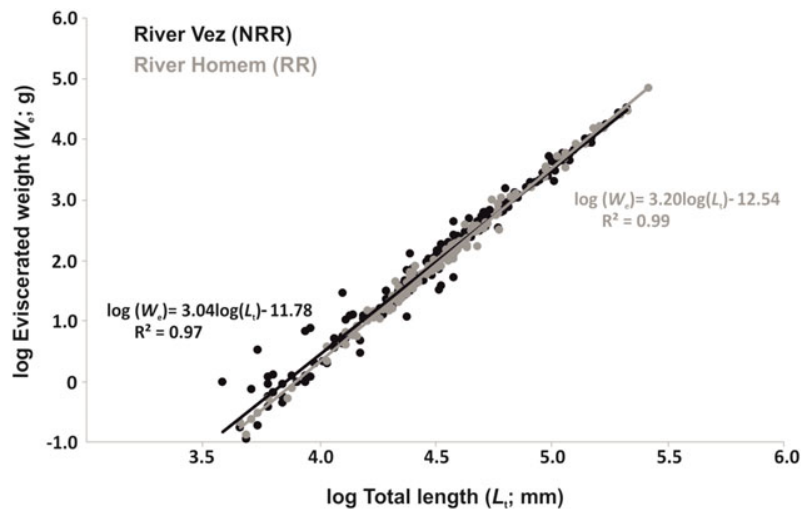

FIGURE 3 Linear weight-length relationships for chubs from the two studied rivers (NRR and RR) and respective fitted linear equations. Immature chubs were included in both sexes. NRR: nonregulated river; RR: regulated river

statistically like isometric growth, chubs from the RR exhibited a significant positive allometric growth type ( $t$ test; $p<0.05$ ), where fish tend to become "plumper" as they increase in length. ANCOVA on log-transformed weight-length relationships revealed significant effects of population/river $\left(F_{1,448}=12.10 ; p<0.001\right)$, and of its interaction with the covariate, log-transformed $L_{t}\left(F_{1,448}=11.20\right.$; $p<0.001$ ), on the linear regressions between log-transformed lengths and weights of tested chubs. The factor $\operatorname{sex}\left(F_{1,448}=0.11 ; p>0.05\right)$, as well as its interactions with $L_{\mathrm{t}}\left(F_{1,448}=0.01 ; p>0.05\right)$ and population/river $\left(F_{1,448}=0.66 ; p>0.05\right)$ did not had a significant effect on this relationship. These results indicate that weight-length relationship is different between the two studied populations, but this variation is dependent of fish ontogeny. Smaller fish have better condition in NRR but, as they grow, adult chubs from RR become plumper and tend to approximate the condition of NRR fish (Figure 3). 


\section{2 | Reproduction}

In this study, age and length at first maturation for studied chub populations from nonregulated and regulated watercourses was determined following two previously described criteria. For the first criteria, age at first maturation was similar between both rivers and was only different between males and females. Male chubs reached maturity at 2 years in both rivers and at a similar minimum size (NRR: 60 mm; RR: 69 mm). Female chubs reached their maturity a year later in both rivers, with 3 years, and at similar minimum sizes (NRR: $94 \mathrm{~mm}$; RR: $90 \mathrm{~mm}$ ). The second criterion used to assess these biological traits confirmed these results, and the observed mean total lengths of the age classes at which the first maturation occurred were the following: NRR males: $72 \mathrm{~mm}\left(2^{+}\right)$; NRR females: $94 \mathrm{~mm}\left(3^{+}\right)$; RR males: $74 \mathrm{~mm}\left(2^{+}\right)$; RR females: $92 \mathrm{~mm}\left(3^{+}\right)$.

Regarding gonad activity (GSI), male chubs presented a similar intra-annual pattern of variation between NRR and RR, with small differences being observed only for the respective peak of the reproductive season (Figure 4). Males inhabiting RR exhibited a shorter duration of this period, reaching its peak in the beginning of May and finishing it almost immediately, whereas NRR chubs prolonged it during the entire month. In short, male chubs from both rivers presented three clearly defined phases: quiescence (August to March), gonad maturation (March to May), and reproduction (May).

For female chubs (Figure 4), differences in gonad maturation pattern were more evident than for males, especially during their reproductive season. As for males, female chubs from both rivers also presented the three annual phases, namely, quiescence (August to March), gonad maturation (March to May or June, depending on the population), and reproduction (May or June, depending on the population). However, NRR female chubs had a slower period of gonad maturation that reached its peak only in the beginning of June coupled with a shorter spawning period, whereas females from RR matured quickly and reached their peak of gonad maturation, and respective spawning, a month earlier, in May, and prolonged it until June.

Multiple regressions performed to identify the main environmental predictors of gonad maturation level (GSI) for male and female chubs from both studied rivers presented distinct results for each sex. None of the proposed environmental variables was selected as being significantly related with male GSI, but for females, the applied analysis $\left(R^{2}=0.72 ; F_{2,19}=10.35 ; p<0.05\right)$ identified DFalls (regression coefficient $=0.76$; standard error $=0.22 ; t=3.43$ ) and $\mathrm{Var}$ (regression coefficient $=-8.49$; standard error $=2.77 ; t=-3.06$ ) as being, respectively, positively, and negatively related with the temporal variation of this biological trait (regression equation: female $\mathrm{GSI}=9.28+0.76$ DFalls-8.49Var).

The PERMANOVA performed to test differences in female chubs' fecundity between both studied rivers identified a significant effect of fish length in the analysed samples $\left(F_{1,83}=37.34 ; p<0.05\right)$. The factor population/river $\left(F_{1,39}=7.54 ; p<0.05\right)$, but not its interaction with covariate, had significant effects on chub fecundity indicating that, independently of their size, female chubs from NRR (approximately 5,200 eggs in average) had a higher fecundity than females from RR (approximately 3,000 eggs in average).

PERMANOVA performed to test differences in oocyte size distribution between female chubs from both studied populations also identified a significant effect of the covariate (i.e., fish length) on the analysed samples $\left(F_{1,203}=5.38 ; p<0.05\right)$. While controlling for this covariate, population/river $\left(F_{1,203}=5.33 ; p<0.05\right)$ showed significant effects on oocyte distribution. Results from these analyses, corroborated by direct observations during oocyte processing, indicate that larger eggs are more common in RR population, associated to only one peak of distribution, whereas females from NRR have a second batch of smaller eggs (Figure 5).

\section{4 | DISCUSSION}

Although being a widely distributed species, especially in northwestern Iberia, which includes the Minho, Lima, Cávado, Douro, Vouga, and Mondego river basins (Carmona \& Doadrio, 2000), only a small number of bioecological studies are available for Northern Iberian chub, dealing with parameters such as density, biomass, age, growth, and reproductive patterns (e.g., Maia et al., 2006; Santos et al., 2004; Valente, 1993). Therefore, the results obtained in this study can contribute to increase knowledge about this taxon and how it responds to environmental variation caused by flow regulation, coupled with EFR implementation, which can help to develop appropriate management strategies for this, or other more threatened, small resident fish species.

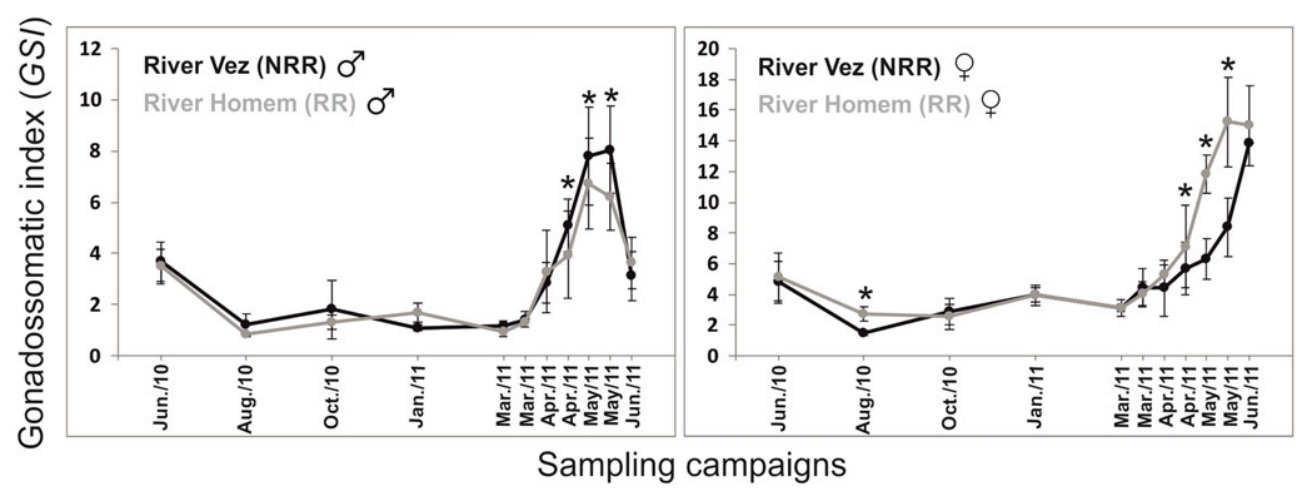

FIGURE 4 Seasonal variation of the gonadossomatic index (GSI; mean \pm standard deviation) for male ( $\gtrsim$ ) and female ( $(+)$ chubs from the two studied populations or rivers. Significant differences of GSI values are indicated $\left(^{*}\right)$ for the respective river or sampling seasons $(t$ tests; $p$ < 0.05). NRR: nonregulated river; RR: regulated river 
FIGURE 5 Size-frequency distribution of oocytes (mean number of observations per size class, considering all subsamples analysed) from female chubs caught in the two studied populations or rivers during the peak of the respective reproductive period (May and June 2011). NRR: nonregulated river; RR: regulated river

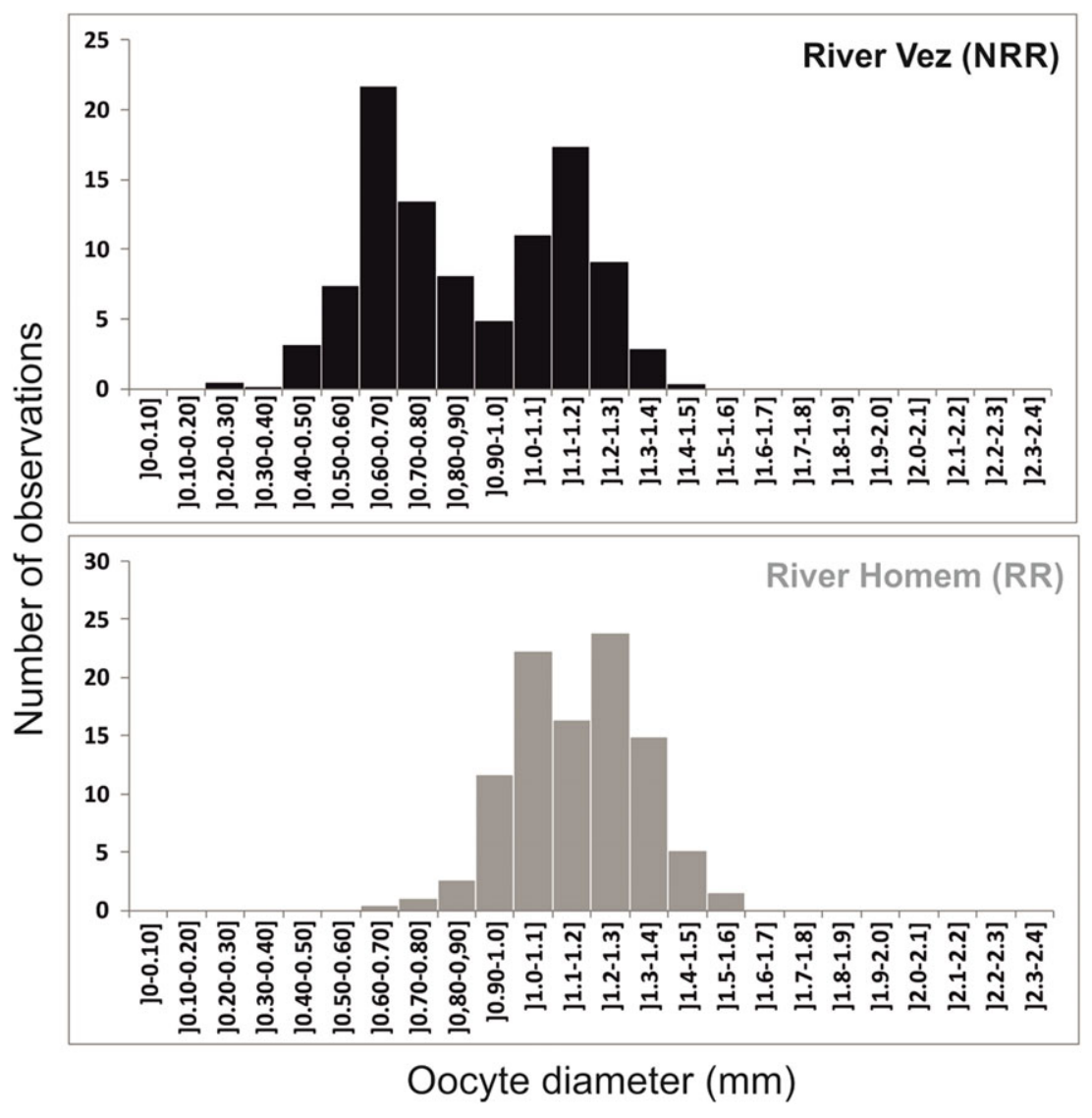

\section{1 | Bioecological differences between nonregulated and regulated scenarios}

Overall, the results obtained in the present study suggest that most lifehistory characteristics of the target species did not present a significant change when facing the studied streamflow regulation scenario not differing substantially between the two studied populations and from those found for other Iberian S. carolitertii populations (e.g., Maia et al., 2006; Valente, 1993), as well as for its sister species, Squalius pyrenaicus (Günther, 1868) populations (e.g., Fernández-Delgado \& Herrera, 1995; Magalhães, 1993). In general, we identified a high degree of segregation between life-cycle patterns of male and female chubs, which was already an expected result because this is relatively common for most species of cyprinids (Mann, 1991). Regarding life-history differences between nonregulated and regulated rivers, only some of the analysed traits of chub populations seemed to respond and be altered by the flow and habitat homogenization caused by the storage dam, and its EFR, on the impounded river.

Weight-length relationship, considered as one of the most appropriate measures of fish condition (Przybylski, Boron, \& Kruk, 2004), was one of the major differences described in this study between the two populations. We found a significant effect of population/river on the type of growth presented by the studied chubs, but, because fish length influenced the obtained relationships, the described pattern is not constant throughout all chub ontogeny. In short, smaller fish have better condition in NRR but, as they grow, adults in RR become plumper and tend to present a similar condition to NRR fish.
Also, the NRR population exhibited an "isometric" growth type, which is common to other populations of the species (Maia et al., 2006; Valente, 1993), whereas RR chubs presented a "positive allometric" growth, revealing an abnormal pattern, which can be assumed as a response to the environmental alteration imposed by the studied dam. Patterns of weight-length relationship and associated insights on fish body condition, usually reflect a combination of various driving forces acting together with environmental variability. In this case, the factor more likely explaining the described patterns is the link between chub's dietary preferences, and its ontogenic variability, and the availability of food resources in both streamflow scenarios. The Northern Iberian chub, as well as other species of this genera, is generally described as an omnivorous species, feeding on both animal and plant items, with a strong ontogenic variation on its dietary habits (e.g., Garrido, Sanchéz-Polaina, \& Prenda, 2003; Magalhães, 1993; Sánchez-Hernández \& Cobo, 2012). As described by these authors, smaller chubs tend to feed more on small soft-bodied invertebrates, which in this case are more available at the NRR river (Alexandre, Sales, et al., 2015), contributing for the higher condition of these fish in the nonregulated watercourse. As they grow, chubs tend to decrease animal prey breadth and feed more on larger items, such as smaller Decapoda and detritus or plant materials (Garrido et al., 2003; Magalhães, 1993), whose constantly higher abundance and availability is incremented in the studied regulated river by the environmental homogenization caused by its storage dam and respective EFR (Alexandre, Sales, et al., 2015), contributing to the higher body condition of adult chubs in RR. 
Besides condition, some reproductive traits of chubs, particularly from females, also exhibited significant differences between the two studied rivers, which can be related with the flow regulation caused by the storage dam and the implemented EFR. Female chubs inhabiting RR presented a quicker maturation and extended spawning periods than females from NRR. Fish from the regulated river also presented a reduced fecundity and a single batch of larger eggs when compared with the females from the nonregulated river, for which a higher fecundity divided by two batches of eggs was observed. Patterns observed for male chubs from NRR and RR and females from NRR were like what is generally described for this, and other congener, species regarding reproductive traits (Fernández-Delgado \& Herrera, 1995; Maia et al., 2006). However, significantly different patterns were observed for RR females, which again may be related with the environmental artificialization imposed by the storage dam on the studied regulated river.

Reproductive cycles of freshwater fish are strongly dependent of the simultaneous occurrence of a set of environmental predictors that provide the optimal conditions for fish to mature and spawn (Humphries et al., 1999). In this study, an increase in gonad activity of female chubs was related with two streamflow variables associated with periods of higher stability of the intra-annual discharge pattern, namely, an increase in the duration of flow falls (DFalls) and a decrease of flow variability (Var). Reproduction of this species happened when optimal conditions of these variables occurred simultaneously, but intraspecific differences on reproductive traits of female chubs between nonregulated and regulated rivers accompanied the specific environmental variability of each of the studied systems. For fish inhabiting northern permanent nonregulated rivers, such as NRR, the end of spring, for example in May, may still not have the ideal conditions for chub's reproduction, as flow variability is often considerably high. In RR, the EFR imposed by its dam causes a decrease of typical spring peak flows and associated environmental variability, allowing female chubs to anticipate the maturation and spawning periods. Also, the higher body condition of adult fish in RR may promote this patterns because the high levels of energy reserves can induce an anticipated and prolonged reproduction (Moyle \& Cech, 1996). Differences obtained for fecundity and oocyte size between the two chub populations, and the relationship of these traits with environmental variability and flow regulation, can be debated at the light of the triangular model of life-history evolution proposed by Winemiller and Rose (1992), which discusses fish life-history strategies as being adaptive with respect to variability, predictability, and seasonality of streamflow regimes (Winemiller, 2005). Within this context, differences of fecundity and oocyte size distribution between the two populations can be discussed as an adaptive response to the specific characteristics of the two flow regimes. Female chubs inhabiting the NRR are subjected to a more variable and unpredictable environment and tend to maximize their reproductive success by producing a large quantity of eggs and releasing them in several batches (i.e., in this case two), similar to what has been described for other cyprinid species as having several advantages for egg and juvenile survival (e.g., Alexandre, Ferreira, et al., 2015; Durham \& Wilde, 2009; Fernández-Delgado \& Herrera, 1995; Herrera \& Fernández-Delgado, 1992; Torralva et al., 1997). In opposition, fish from RR face a more constant and predictable environment, with less prominence to egg and juvenile mortality, so the investment they do on the number of eggs and batches released, is also reduced.

\section{2 | Migratory vs resident fish species}

Annual variation in the hydrograph should affect species with distinct life-history strategies differently, thus determining variation in the composition and structure of fish assemblages (Agostinho, Gomes, Veríssimo, \& Okada, 2004). Considering this, the responses obtained in this study for the target non-migratory species, the Iberian chub, to the studied flow regulation scenario, can be compared with the results previously obtained (Alexandre, Ferreira, et al., 2015) for a larger and more mobile fish species, the Iberian barbel (L. bocagei), and provide novel insights about the way how different fish species cope with imposed environmental conditions.

In general, (check Table 4 for a summary of the different responses exhibited by both species to the same type of flow regulation), life-history traits of the target non-migratory species were similar between the two rivers and the only significant responses to artificial environmental homogeneity imposed by the storage dam were reflected mostly by female fish through changes in the duration of spawning period, fecundity, and oocyte size distribution. Only fish condition showed a response to flow regulation for both sexes. In opposition, flow regulation was associated with wider responses from the migratory species (Iberian barbel), most of them common to males and females, reflected by an altered seasonal growth pattern, a decrease of fish growth rates, body condition and gonad activity, and an increase of maximum length and longevity. The two species presented contradictory results when facing the same type of flow regulation, which proves the complexity of the existing relationships between fish biological cycles, life history strategies, and environmental variability (e.g., Alexandre, Ferreira, et al., 2015; Mims \& Olden, 2012, 2013). However, considering the results obtained for the present and previous studies, the migratory species seem to exhibit a high degree of change in their biological cycles, both in terms of growth and reproduction, in relation to artificially induced environmental homogenization than the studied resident species. This is probably related with the specific life-history strategies and cycles and associated cues and habitat requirements of both types of species.

In general, migratory and high-mobile species, like the potamodromous lberian barbel, have a high reliance on habitat and environmental features to complete their different life-history processes (Lennox et al., 2016; Lucas \& Baras, 2001). Ultimately, at specific stages or periods of their annual and seasonal cycle (e.g., migration, growth, and reproduction), they tend to display reophilic behaviour and/or present demographic strategies particularly mediated by the timing and intensity of flow and temperature cues (Pavlov, Mikheev, Lupandin, \& Skorobogatov, 2008; Skov et al., 2010), variables that are usually less important (i.e., confirmed by the poor relationships obtained in this study between chub's seasonal growth or GSI and environmental predictors) for the development of the more flexible and generalist life-cycle strategies of resident species (Lucas 


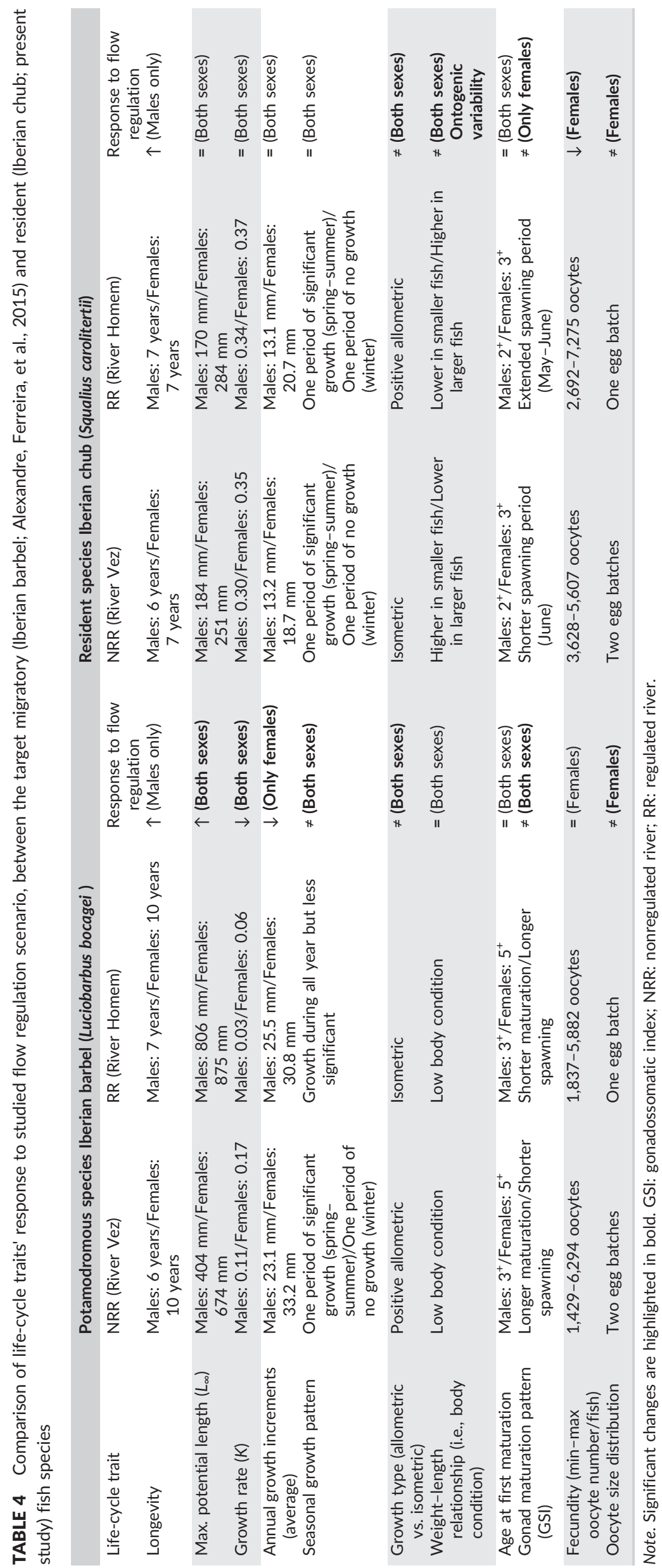


\& Baras, 2001; Tedesco et al., 2008). These aspects make migratory fish more susceptible and responsive than non-migratory ones to environmental changes caused by river regulation, and they often show a higher biological deviation when subjected to the environmental differences that exist between natural and regulated flow regimes (Naiman, Latterell, Pettit, \& Olden, 2008), similarly to what was observed in the comparison presented in this study. Most flow regulation modes, but especially EFR regimes, tend to homogenize downstream habitats and environmental conditions, with loss of the typical fluvial variability and reduction or alteration of environmental cues that migratory fish require for the development of most of their ecological processes, such as migration, growth, or reproduction (Araújo et al., 2013).

\section{3 | Management applications}

The interface between water use and management by human populations and the maintenance of the integrity of aquatic ecosystems represents a difficult challenge to resource managers (Postel, Daily, \& Ehrlich, 1996). An integral part of the strategy for meeting this challenge is to understand how past and present water management has affected the flow regime of river ecosystems and how the resulting flow regimes have affected aquatic biota (Brown \& Bauer, 2010). Findings presented in this study corroborate the assumption that some life history traits of cyprinid fish species can be significantly altered downstream of dams, in the order of only a few decades and promote a high degree of intraspecific and interspecific differences in response to flow regulation. This type of evaluation of the interplay between environmental variability, its artificialization, and bioecological cycles of different fish species is of increasing importance nowadays, especially within the joint contexts of increasing river fragmentation, flow regulation by dams, and climate change (Xenopoulos et al., 2005). This study was developed for only a 1 year period and does not encompass all the typical interannual environmental variability of Mediterranean rivers, so its use for management purposes should be addressed carefully and in a proper context. However, and considering that 2010-2011 was a normal climate year, findings from this study can have a wide multiple-scenario application and will be important to understand the derivation in biological patterns imposed by increasing river regulation on freshwater fish species and to be used as guiding elements for flow requirements implementations (Arthington, 2012; Palmer et al., 2008). Results could be also applicable to other small resident cyprinids (e.g., Squalius sp.) across Europe, some of them sharing similar habitats (i.e., permanent rivers) or facing identical human pressures (i.e., streamflow regulation).

\section{ACKNOWLEDGEMENTS}

The authors wish to thank Ana Ferreira, Catarina Mateus, Joana Ribeiro, Marta Candeias, Marta Lourenço, Nuno Andrade, Paula Valadas and Tadeu Pereira for their assistance during multiple sampling campaigns and laboratorial sessions. This study had the support of the Portuguese Science Foundation (FCT) through its pluriannual funding programme to MARE (UID/MAR/04292/2013) and through postdoctoral support granted to C. M. Alexandre (SFRH/BPD/ 108582/2015).

\section{ORCID}

Carlos M. Alexandre (D) http://orcid.org/0000-0003-2567-4434

\section{REFERENCES}

Agostinho, A. A., Gomes, L. C., Veríssimo, S., \& Okada, E. K. (2004). Flood regime, dam regulation and fish in the Upper Paraná River: Effects on assemblage attributes, reproduction and recruitment. Reviews in Fish Biology and Fisheries, 14, 11-19.

Alexandre CM. 2014. Ecological impact of streamflow variability in the bioecology of freshwater fishes from permanent and temporary Mediterranean river systems. Ph.D. thesis, University of Évora. 243 pp.

Alexandre, C. M., Ferreira, M. T., \& Almeida, P. R. (2013). Fish assemblages in non-regulated and regulated rivers from permanent and temporary Iberian systems. River Research and Applications, 29, 1042-1058.

Alexandre, C. M., Ferreira, M. T., \& Almeida, P. R. (2015). Life-history of a cyprinid species within non-regulated and regulated rivers from permanent and temporary Mediterranean basins. Ecohydrology, 8, 1137-1153.

Alexandre, C. M., Sales, S., Ferreira, M. T., \& Almeida, P. R. (2015). Food resources and cyprinid diet in permanent and temporary Mediterranean rivers with natural and regulated flow. Ecology of Freshwater Fish, 24, 629-645.

Anderson, M. J., Gorley, R., \& Clarke, K. R. (2008). PERMANOVA for PRIMER: Guide to software and statistical methods. Plymouth, United Kingdom: PRIMER-E Ltd.

Araújo, E. S., Marques, E. E., Freitas, I. S., Neuberger, A. L., Fernandes, R., \& Pelicice, R. M. (2013). Changes in distance decay relationships after river regulation: Similarity among fish assemblages in a large Amazonian river. Ecology of Freshwater Fish, 22, 543-552.

Arthington, A. H. (2012). Environmental flows: Saving rivers in the third millennium. Los Angeles, California, USA: University of California Press.

Bagenal, T. B., \& Tesch, F. W. (1978). Age and growth. In T. Bagenal (Ed.), Methods for assessment of fish production in fresh waters (3rd ed.) (pp. 101-136). Oxford: IBP Handbook, Blackwell Science Publications.

Baltz, D. M., \& Moyle, P. (1984). Segregation by species and size class of rainbow trout (Salmo gairdneri) and Sacramento sucker (Catostomus occidentalis) in three California streams. Environmental Biology of Fishes, 10, 101-110.

Baylis, J. R., Wiegman, D. D., \& Hoff, M. (1993). Alternating life histories of smallmouth bass. Transactions of the American Fisheries Society, 122, 500-510.

Blanck, A., Tedesco, P. A., \& Lamouroux, N. (2007). Relationships between life-history strategies of European freshwater fish species and their habitat preferences. Freshwater Biology, 52, 843-859.

Brown, L. R., \& Bauer, M. L. (2010). Effects of hydrologic infrastructure on flow regimes of California's Central Valley rivers: Implications for fish populations. River Research and Applications, 26, 751-765.

Bunn, S. E., \& Arthington, A. H. (2002). Basic principles and ecological consequences of altered flow regimes for aquatic biodiversity. Environmental Management, 30, 492-507.

Carmona, J. A., \& Doadrio, I. (2000). Threatened fishes of the world: Leuciscus carolitertii Doadrio, 1988 (Cyprinidae). Environmental Biology of Fishes, 57, 96.

Durham, B. W., \& Wilde, G. R. (2009). Effects of streamflow and intermittency on the reproductive success of two broadcast-spawning cyprinid fishes. Copeia, 2009(1), 21-28.

Fernández-Delgado, C., \& Herrera, M. (1995). Age structure, growth and reproduction of Leuciscus pyrenaicus in an intermittent steam in the Guadalquivir river basin, Southern Spain. Journal of Fish Biology, 46, 371-380. 
Garrido, F. B., Sanchéz-Polaina, F. J., \& Prenda, J. (2003). Summer diet of the Iberian chub (Squalius pyrenaicus) in a Mediterranean stream in Sierra Morena (Yeguas stream, Córdoba, Spain). Limnetica, 22, 99-106.

Gayanilo, F. C., Sparre, P., \& Pauly, D. (2004). The FAO-ICLARM stock assessment tools II Windows version (FISAT II) users guide (Revision I). FAO Computerized Information Series (Fisheries), 8, 183.

Herrera, M., \& Fernández-Delgado (1992). The life-history patterns of Barbus bocagei sclateri (Günther, 1868) in a tributary stream of the Guadalquivir River Basin, Southern Spain. Ecology of Freshwater Fish, 1, 42-51.

Humphries, P., King, A. J., \& Koehn, J. D. (1999). Fish, flows and floodplains: Links between freshwater fishes and their environment in the MurrayDarling River system, Australia. Environmental Biology of Fishes, 56, 129-151.

INAG I. P 2008. Tipologia de rios em Portugal Continental no âmbito da implementação da Directiva Quadro da Água-Caracterização abiótica. Ministério do Ambiente, do Ordenamento do Território e do Desenvolvimento Regional, Instituto da Água, Lisboa.

IPMA I.P (2011). Boletim Climatológico Anual 2010-2011. Lisboa: Ministério do Mar.

Junk, W. J., Bayley, P. B., \& Sparks, R. E. (1989). The flood pulse concept in river-floodplain systems. In D. P. Lodge (Ed.), Proceedings of the international large river symposium (pp. 110-127). Ottawa, ON: Canadian Special Publication of Fisheries and Aquatic Sciences, Fisheries and Oceans Canada.

Lamouroux, N., Poff, N. L., \& Angermeier, P. L. (2002). Intercontinental convergence of stream fish community traits along geomorphic and hydraulic gradients. Ecology, 83, 1792-1807.

Lennox, R. J., Chapman, J. M., Souliere, C. M., Tudorache, C., Wikelski, M. Metcalfe, J. D., \& Cooke, S. J. (2016). Conservation physiology of animal migration. Conservation Physiology, 4, 1-15.

Lucas, M. C., \& Baras, E. (2001). Migration of freshwater fishes. Oxford, UK Blackwell Science.

Magalhães, M. F. (1993). Effects of season and body-size on the distribution and diet of the Iberian chub Leuciscus pyrenaicus in a lowland catchment. Journal of Fish Biology, 42, 875-888.

Maia, H. M. S., Maia, C. F. Q., Pires, D. F. C., \& Valente, A. C. N. (2006). Biology of the Iberian chub (Squalius carolitertii) in an atlantic-type stream (river Lima basin-north Portugal). A Preliminary Approach. Limnetica, 25, 713-722.

Mann, R. H. K. (1991). Growth and production. In I. J. Winfield, \& J. S. Nelson (Eds.), Cyprinid fishes, systematic, biology and exploitation (pp. 456-482). London: Chapman \& Hall.

Marsh, N. A., Stewardson, M. J., \& Kennard, M. J. (2006). River analysis package. Melbourne: Cooperative Research Centre for Catchment Hydrology. Monash University.

Matono, P., Ilhéu, M., Formigo, N., Ferreira, M. T., Almeida, P. R., Cortes, R., \& Bernardo, J. (2009). Tipologia fluvial com base no elemento peixes para Portugal Continental. Recursos Hidricos, 30(2), 39-46.

Mims, M. C., \& Olden, J. D. (2012). Life history theory predicts fish assemblage response to hydrologic regimes. Ecology, 93, 35-45.

Mims, M. C., \& Olden, J. D. (2013). Fish assemblages respond to altered flow regimes via ecological filtering of life history strategies. Freshwater Biology, 58, 50-62.

Moyle, P. B., \& Cech, J. J. (1996). Fishes: An introduction to ichthyology. New Jersey.

Murua, H., Kraus, G., Saborido-Rey, F., Witthames, P. R., Thorsen, N., \& Junquera, S. (2003). Procedure to estimate fecundity of marine fish species in relation to their reproductive strategy. Journal of Northwestern Atlantic Fisheries Science, 33, 33-54.

Naesje, T., Jonsson, B., \& Skurdal, J. (1995). Spring flood: A primary cue for hatching of river spawning Coregoninae. Canadian Journal of Fisheries and Aquatic Sciences, 52, 2190-2196.
Naiman, R. J., Latterell, J. J., Pettit, N. E., \& Olden, J. D. (2008). Flow variability and the vitality of river system. Comptes Rendus Geoscience, 340, 629-643.

Olden, J. D., \& Naiman, R. J. (2010). Incorporating thermal regimes into environmental flows assessments: Modifying dam operations to restore freshwater ecosystem integrity. Freshwater Biology, 55, 86-107.

Palmer, M. A., Reidy-Liermann, C., Nilsson, C., Florke, M., Alcamo, J., Lake, P. S., \& Bond, N. (2008). Climate change and the world's river basins: Anticipating management options. Frontiers in Ecology and the Environment, 6, 81-89.

Pavlov, D. S., Mikheev, V. N., Lupandin, A. I., \& Skorobogatov, M. A. (2008). Ecological and behavioural influences on juvenile fish migrations in regulated rivers: A review of experimental and field studies. Hydrobiologia, 609, 125-138.

Poff, N. L., Allan, J. D., Bain, M. B., Karr, J. R., Prestegaard, K. L., Richter, B. D., ... Stromberg, J. C. (1997). The natural flow regime. Bioscience, 47(11), 769-784.

Poff, N. L., \& Zimmerman, J. K. (2010). Ecological responses to altered flow regimes: A literature review to inform the science and management of environmental flows. Freshwater Biology, 55(1), 194-205.

Postel, S. L., Daily, G. C., \& Ehrlich, P. R. (1996). Human appropriation of renewable fresh water. Science, 271, 785-788.

Przybylski, M., Boron, A., \& Kruk, A. (2004). Growth of barbel, Barbus barbus (L.) in the upper Warta River, Odra River system. Ecohydrology and Hydrobiology, 4, 183-190.

Resh, V. H., Brown, A. V., Covich, A. P., Gurtz, M. E., Li, H. W., Minshall, W., ... Wissmar, C. (1988). The role of disturbance in stream ecology. Journal of North American Benthological Society, 7, 433-455.

Sánchez-Hernández, J., \& Cobo, F. (2012). Ontogenic dietary shifts and food selection of endemic Squalius carolitertii (Actinopterygii: Cypriniformes: Cyprinidae) in River Tormes, Central Spain, in summer. Acta Ichthyologica et Piscatoria, 42, 101-111.

Santa-Maria, C. M., \& Yuste, J. F. (2010). IARHIS 2.2. Indicators of hydrologic alteration in rivers. Metodological reference manual. Madrid.

Santos, J. M., Godinho, F., \& Ferreira MT Cortes, R. (2004). The organisation of fish assemblages in the regulated Lima basin, Northern Portugal. Limnologica, 34, 224-235.

Skov, C., Aarestrup, K., Baktoft, H., Brodersen, J., Brönmark, C., Hansson, L. A., ... Nilsson, P. A. (2010). Influences of environmental cues, migration history, and habitat familiarity on partial migration. Behavioural Ecology, 21, 1140-1146. https://doi.org/10.1093/beheco/arq121

SNIRH. 2013. http://www.snirh.pt.

Spranza, J. J., \& Stanley, E. H. (2000). Condition, growth, and reproductive styles of fishes exposed to different environmental regimes in a prairie drainage. Environmental Biology of Fishes, 59, 99-109.

Tedesco, P. A., Hugueny, B., Oberdorff, T., Durr, H. H., Merigoux, S., \& Merona, B. D. (2008). River hydrological seasonality influences life history strategies of tropical riverine fishes. Oecologia, 156, 691-702.

Torralva, M., Puig, A., \& Fernández-Delgado, C. (1997). Effect of river regulation on the life-history patterns of Barbus sclateri in the Segura river basin (south-east Spain). Journal of Fish Biology, 51, 300-311.

Valente ACN. 1993. Biologia e dinâmica das populacões de truta-de-rio, Salmo trutta L., da bacia hidrográfica do rio Lima. Ph. D Thesis, University of Porto. 244 pp.

Weisberg, S. B., \& Burton, W. H. (1993). Enhancement of fish feeding and growth after an increase in minimum flow below the Conowingo Dam. North American Journal of Fisheries Management, 13, 103-109.

Welcomme, R. L., Bene, C., Brow, C. A., Arthington, A., Patrick Dugan, P., King, J. M., \& Sugunan, V. (2006). Predicting the water requirements of river fisheries. In J. T. A. Verhoeven, B. Beltman, R. Bobbink, \& D. F. Whigham (Eds.), Wetlands and natural resource management. Berlin, Germany: Springer-Verlag. 
Winemiller, K. O. (2005). Life history strategies, population regulation, and implications for fisheries management. Canadian Journal of Fisheries and Aquatic Sciences, 52, 872-885.

Winemiller, K. O., \& Rose, K. A. (1992). Patterns of life-history diversification in North American fishes: Implications for population regulation. Canadian Journal of Fisheries and Aquatic Sciences, 49, 2196-2218.

Xenopoulos, M., Lodge, D. M., Alcamo, J., Märker, M., Schulze, K., \& Van Vuuren, D. P. (2005). Scenarios of freshwater fish extinctions from climate change and water withdrawal. Global Change Biology, 11, 1557-1564.
How to cite this article: Alexandre CM, Ferreira MT, Almeida PR. Life-cycle responses of a Mediterranean non-migratory cyprinid species, the Northern Iberian chub (Squalius carolitertii Doadrio, 1988), to streamflow regulation. Ecohydrology. 2018;

11:e1998. https://doi.org/10.1002/eco.1998 